\title{
Success rate of adrenal venous sampling and predictors for success: a retrospective study
}

\author{
Thorsang Chayovan ${ }^{1 A, B, D, F}$, Padiporn Limumpornpetch ${ }^{2 A, D}$, Keerati Hongsakul ${ }^{1 A, C, D, E, F}$ \\ 'Division of Interventional Radiology, Department of Radiology, Faculty of Medicine, Prince of Songkla University, Thailand \\ ${ }^{2}$ Division of Endocrinology, Department of Internal Medicine, Faculty of Medicine, Prince of Songkla University, Thailand
}

\section{Abstract}

\begin{abstract}
Purpose: To report the success rate of adrenal venous sampling (AVS) and identify the predictors for procedural success.

Material and methods: Sixty-four patients (18 men and 46 women) with a mean \pm SD age of $50 \pm 11.8$ years (range 28-69 years) diagnosed as primary hyperaldosteronism, and who underwent AVS from January 2009 to December 2016, were retrospectively reviewed. In our institution, the initial period to perform the AVS was set from 2009 to 2013 , and the post-initial period was defined as procedures performed after 2013. Successful sampling was determined when the ratio of cortisol from the adrenal vein to the level of cortisol in the inferior vena cava $\geq 5$. The procedural success and subject factors between success and failure were analysed. A $p$ value $<0.05$ was considered statistically significant.

Results: The success rate of bilateral AVS was 71.9\%. The success rates of right and left AVS were $76.6 \%$ and $90.6 \%$, respectively. Male patients were more likely to succeed than female patients (adjusted odds ratio [aOR], 9.83; $95 \%$ confidence interval $[\mathrm{CI}], 1.14-85.14 ; p=0.009$ ). In our institution, the procedure performed in the post-initial period also succeeded more often compared to the initial period (aOR, 5.05; 95\% CI, 1.2-21.16; $p=0.017$ ). No other factors were associated with the success rate in this study.
\end{abstract}

Conclusions: The success rate of bilateral AVS in our institution was rather high. Male gender and procedure performed in the post-initial period were significant predictive factors for a successful procedure.

Key words: primary aldosteronism, adrenal venous sampling, success, predictive factor.

\section{Introduction}

Primary aldosteronism (PA) affects more than 10\% [1-3] of all hypertensive patients, of which the two main causes are unilateral aldosterone-producing adenoma (APA) and bilateral adrenal hyperplasia (BAH) [2-5]. Distinguishing the two diagnoses is critical because APA is curable by resection while $\mathrm{BAH}$ is treated with medication $[1,2,4,5]$. Computed tomography (CT) and magnetic resonance image (MRI) are the preferred modalities to detect adrenal adenoma. However, they only help for detection and anatomical diagnosis but cannot determine the biological differentiation between APA and BAH [6].

Adrenal venous sampling (AVS) is the gold standard to diagnose APA and BAH using the ratio of plasma aldosterone to cortical levels between both sides [6-9]. However, AVS is an invasive and difficult procedure even in experienced hands $[1,7,8]$. A previous publication reported variable success rates of the procedure ranging from $42 \%$ to $98 \%$ [4-6,10], while complications included groin haematoma, venous thrombosis, venous transection, adrenal haemorrhage, adrenal insufficiency, and hypertensive

Correspondence address:

Assist. Prof. Keerati Hongsakul, Division of Interventional Radiology, Department of Radiology, Faculty of Medicine, Prince of Songkla University, Thailand,

e-mail: hkeerati@medicine.psu.ac.th

Authors' contribution:

A Study design · B Data collection · C Statistical analysis · D Data interpretation · E Manuscript preparation · F Literature search · G Funds collection 
crisis $[6,8,11]$. Catheterisation into the right adrenal vein is the main difficulty because of the anatomical factors, which include small diameter, short length, and direct drainage into the inferior vena cava (IVC). In contrast, blood sampling from the left adrenal vein is relatively easy due to consistent anatomy. Previous publications reported success rates of right and left blood samplings of 40-94\% and more than $90 \%$, respectively $[6,8,12-15]$.

As mentioned, AVS is the gold standard procedure to determine the cause of PA; however, the success rate of the procedure varies. Also, the success rate of the procedure should be a factor in considering the benefits of the investigation. However, there are few data that report the factors of determining success. The objective of this study was to report the success rates of AVS in our hospital and identify the predictors of procedural success.

\section{Material and methods}

\section{Patients}

This was a retrospective study of all patients who were diagnosed with PA by saline-loading testing or fludrocortisone challenge testing and underwent AVS from January 2009 to December 2016 in Songklanagarind Hospital, which is a university hospital in southern Thailand. Sixtyseven patients who met the inclusion criteria included those diagnosed with PA by clinical and laboratory data as well as the presence of nodules on CT scan or MRI. However, three patients declined the procedure and were excluded. Consequently, the study population included 64 patients. The present study was approved by the Ethics Committee of the Faculty of Medicine, Prince of Songkla University (IRB No. 58-243-07-4).

\section{Procedure}

The intravenous infusion consisted of cosyntropin (Synacthen $^{\circledR}$, Novartis Pharmaceuticals, Dorval, Québec, Canada) $0.25 \mathrm{mg}$ in $500 \mathrm{ml}$ of $5 \%$ dextrose in water infused at $100 \mathrm{ml} / \mathrm{h}$ for at least 30 minutes before the AVS. The procedure was performed by standard percutaneous transfemoral vein catheterisation using a 5-French $(\mathrm{Fr})$ sheath under local anaesthesia. A 5-Fr angiographic catheter using a Cobra with one side-hole (Terumo Europe, Leuven, Belgium) was used for catheterisation into the right adrenal vein and a Simon II (Boston Scientific, MA, USA) for catheterisation into the left adrenal vein. A $6 \mathrm{ml}$ sample of blood was taken from each adrenal vein, and $10 \mathrm{ml}$ of blood was sampled from the IVC. The sample evaluated the cortisol ratio to confirm successful catheterisation. Haemostasis at the puncture site was assured by manual compression. In our hospital, AVS was performed by fluoroscopic guidance by digital subtraction angiography (INTEGRIS V5000; Philips, Best, The Netherlands) from 2009 to 2013 (initial period). Additionally, there were four interventional radiologists performing AVS during the initial period. After 2013 (post-initial period), AVS was performed by single-plane digital subtraction angiography (Allura Xper FD; Philips, Best, The Netherlands). However, AVS in this period was performed by a single interventional radiologist who specialised in venous intervention.

\section{Data collection}

The data were retrieved from the Radiology Department records and the hospital database. The collected data included the patients' demographic data and technical factors including time of operation, number of correct blood samplings, route of access, and the initial and post-initial periods to perform the procedure.

\section{Definitions}

The final success of AVS was defined as a ratio of $\geq 5$ (selectivity index) of the levels of cortisol from each of the left and right adrenal veins to the level of cortisol from the IVC. Failure of the procedure was defined as a selectivity index $<5$ from one or two sides. In the cases where blood samples could not be collected from one or both adrenal veins, this was also defined as procedural failure. We also analysed the success of each AVS to determine the outcome.

\section{Statistical analysis}

Continuous demographic and technical data are presented as mean \pm standard deviation (SD) and range. Categorical data are presented by frequency and percentage. Continuous data of predictive factors for success are represented by Student's $t$-test and Wilcoxon rank sum test, and the categorical data of predictors for success were calculated by $\chi^{2}$ and Fisher's exact tests. The significant predictive factors from univariate analysis were also calculated by multivariate logistic regression. A $p$ value less than 0.05 was considered statistically significant.

\section{Results}

This study included 64 patients who underwent AVS in our hospital. The number of AVS procedures in this centre was seven to nine procedures per year. The demographic and technical data are shown in Table 1 . Our subjects were predominately female (46 patients). The mean age \pm SD was $50 \pm 11.8$ years, and the mean $\mathrm{BMI} \pm$ SD was 25.8 $\pm 5.1 \mathrm{~kg} / \mathrm{m}^{2}$. The mean \pm SD systolic and diastolic blood pressures were $148 \pm 21 \mathrm{mmHg}$ and $89 \pm 13 \mathrm{mmHg}$, respectively. Most patients had nodules (48.4\%) on the left adrenal gland. AVS was performed mostly via the right common femoral vein approach $(90.6 \%)$.

The success rates are presented in Table 2 . The success rates of right and left blood samplings were $76.6 \%$ and 
$90.6 \%$, respectively. The final success rate of the procedure was $71.9 \%$. Failure of procedure was found in three patients. Failure to collect blood from the right adrenal vein with a left selectivity index of $<5$ was found in two patients. Another case had a selectivity index $<5$ from both sides. The success rates of right and left adrenal blood samplings in male vs. female were $94.4 \%$ vs. $69.9 \%$ $(p=0.048)$ and $100 \%$ vs. $87 \%(p=0.173)$, respectively. The success of right and left adrenal samplings performed in the initial five-year and post-initial three-year periods were $67.6 \%$ vs. $88.9 \%(p=0.091)$ and $83.8 \%$ vs. $100 \%$ $(p=0.035)$, respectively. The details of success of procedure are shown in Table 3. Univariate analysis was used to identify factors affecting the success of the procedure. The results showed statistical significance of two factors that included gender $(p=0.005)$ and the period of procedure $(p=0.007)$.

The significant predictive factors are shown in Table 4. By multivariate logistic analysis, the gender and the period of procedure were confirmed to be significant factors associated with success. Success of the procedure in male patients was about 10 times greater than in female patients (adjusted odds ratio [aOR], 9.83; 95\% confidence interval [CI], 1.14-85.14; $p=0.009$ ). Success of the procedure performed in the post-initial period in our institute was five times greater than in the initial period $(\mathrm{aOR}, 5.05$; $95 \%$ CI, 1.2-21.16; $p=0.017$ ).

\section{Discussion}

In the current study, the final success rate of AVS was in the range of success rates from previous reports $[4-6,10]$. When an evaluation of the success rates was performed for each side, we found the success rate of blood sampling from the left side was higher than from the right side. Gender and the period of the procedure were the only two significant predictive factors of success associated with the high odds ratios in this study. The other variables were not significant factors to determine success.

The final success rate in this study was $71.9 \%$, which was rather high compared to previous studies [4-6,10] because of the influence of the result of the initial first five experiences (2009-2013), showing a 59\% success rate. Additionally, our centre is a low-volume centre, which performs less than 20 AVS procedures per year. However, the success rate increased to $89 \%$ in the post-initial threeyear period (2014-2016). Similar results were reported by Jakobsson et al. [14] and Siracuse et al. [16], who showed increased success rates after their initial period from 38\% to $92 \%$ and from $58 \%$ to $82 \%$, respectively. Better outcomes were due to the gains in experience and skill.

The success rates of the right and left AVS in this study were $76.6 \%$ and $90.6 \%$, respectively. The success rate of the right AVS was reported to range from $81 \%$ to $97 \%$ in experienced interventionists, while the success rates were $40 \%$ to $80 \%$ in low-volume centres or from less
Table 1. Patients' demographic data and technical parameters

\begin{tabular}{|c|c|}
\hline Parameters & $n(\%)$ \\
\hline Patients & \\
\hline Age (mean $50 \pm 11.8$ years; range $28-69$ years) & \\
\hline Gender & \\
\hline $\begin{array}{l}\text { Male } \\
\text { Female }\end{array}$ & $\begin{array}{l}18(28.1) \\
46(71.9)\end{array}$ \\
\hline Height (mean, $1.6 \pm 1.0 \mathrm{~m}$; range $1.45-1.80 \mathrm{~m}$ ) & \\
\hline Weight (mean, $64.8 \pm 15.2 \mathrm{~kg} ; 40.5-85 \mathrm{~kg}$ ) & \\
\hline BMI (mean $\left.25.8 \pm 5.1 \mathrm{~kg} / \mathrm{m}^{2}\right)$ & \\
\hline $\begin{array}{l}<23 \\
\geq 23\end{array}$ & $\begin{array}{l}32(50) \\
32(50)\end{array}$ \\
\hline $\begin{array}{l}\text { Systolic } B P \text { (mean, } 147.9 \pm 21.1 \mathrm{mmHg} \text {; } \\
\text { range } 110-230 \mathrm{mmHg} \text { ) }\end{array}$ & \\
\hline Diastolic BP (mean, $89 \pm 13 \mathrm{mmHg}$; range 52-114 mmHg) & \\
\hline Aldosterone (mean, $78.6 \pm 48.4 \mathrm{ng} / \mathrm{dl}$; range 11-307 ng/dl) & \\
\hline Potassium (mean, $3 \pm 0.7 \mathrm{mEq} / \mathrm{l}$; range $1.9-4.9 \mathrm{mEq} / \mathrm{l}$ ) & \\
\hline Adrenal nodule (side) & \\
\hline $\begin{array}{l}\text { None } \\
\text { Right side } \\
\text { Left side } \\
\text { Both sides }\end{array}$ & $\begin{array}{c}2(3.1) \\
28(43.8) \\
31(48.4) \\
3(4.7) \\
\end{array}$ \\
\hline Visibility of right adrenal vein & \\
\hline $\begin{array}{l}\text { Present on CT/MRI } \\
\text { Non-present on CT/MRI }\end{array}$ & $\begin{array}{c}60(93.7) \\
4(6.3)\end{array}$ \\
\hline Technique & \\
\hline Time of procedure & \\
\hline $\begin{array}{l}\text { Morning } \\
\text { Afternoon }\end{array}$ & $\begin{array}{l}39(60.9) \\
25(39.1)\end{array}$ \\
\hline Route of access & \\
\hline $\begin{array}{l}\text { Right common femoral vein } \\
\text { Left common femoral vein } \\
\text { Both common femoral veins }\end{array}$ & $\begin{array}{c}58(90.6) \\
5(7.8) \\
1(1.6)\end{array}$ \\
\hline Number of right blood samplings per procedure & \\
\hline $\begin{array}{l}\text { One } \\
\text { Two } \\
\text { No sampling }\end{array}$ & $\begin{array}{l}36(56.3) \\
26(40.6) \\
2(3.1)\end{array}$ \\
\hline Period of procedure & \\
\hline $\begin{array}{l}2009-2013 \\
2014-2016\end{array}$ & $\begin{array}{l}37(57.8) \\
27(42.2)\end{array}$ \\
\hline
\end{tabular}

BMI - body mass index, BP - blood pressure, CT - computed tomography, $\mathrm{MRI}$ - magnetic resonance imaging

\section{Table 2. Success rates of adrenal venous sampling}

\begin{tabular}{|l|c|c|c|}
\hline $\begin{array}{l}\text { Adrenal venous } \\
\text { sampling }\end{array}$ & $\begin{array}{c}\text { Right } \\
n(\%)\end{array}$ & $\begin{array}{c}\text { Left } \\
n(\%)\end{array}$ & $\begin{array}{c}\text { Bilateral } \\
n(\%)\end{array}$ \\
\hline Success & $49(76.6)$ & $58(90.6)$ & $46(71.9)$ \\
\hline Failure & $15(23.4)$ & $6(9.4)$ & $18(28.1)$ \\
\hline
\end{tabular}


Table 3. Univariate analysis for success of blood sampling $(n=64)$

\begin{tabular}{|c|c|c|c|c|c|c|c|c|c|}
\hline \multirow[t]{2}{*}{ Factors } & \multicolumn{3}{|c|}{ Right AVS } & \multicolumn{3}{|c|}{ Left AVS } & \multicolumn{3}{|c|}{ Both AVS } \\
\hline & $\begin{array}{c}\text { Success } \\
n=49\end{array}$ & $\begin{array}{l}\text { Failure } \\
n=15\end{array}$ & $p$ & $\begin{array}{c}\text { Success } \\
n=58\end{array}$ & $\begin{array}{c}\text { Failure } \\
n=6\end{array}$ & $p$ & $\begin{array}{c}\text { Success } \\
n=46\end{array}$ & $\begin{array}{l}\text { Failure } \\
n=18\end{array}$ & $p$ \\
\hline \multicolumn{10}{|l|}{ Patients } \\
\hline Age (year), mean $( \pm S D)$ & $49.8(11.1)$ & $50.7(14.4)$ & 0.805 & $50(11.9)$ & $50.2(12.3)$ & 0.971 & $49.4(11.1)$ & $51.4(13.6)$ & 0.545 \\
\hline \multicolumn{10}{|l|}{ Gender } \\
\hline $\begin{array}{l}\text { Male } \\
\text { Female }\end{array}$ & $\begin{array}{l}17 \\
32\end{array}$ & $\begin{array}{c}1 \\
14\end{array}$ & $0.048^{*}$ & $\begin{array}{l}18 \\
40\end{array}$ & $\begin{array}{l}0 \\
6\end{array}$ & 0.173 & $\begin{array}{l}17 \\
29\end{array}$ & $\begin{array}{c}1 \\
17\end{array}$ & $0.005^{*}$ \\
\hline Height $(m)$, mean $( \pm S D)$ & $\begin{array}{c}1.6 \\
(0.1)\end{array}$ & $\begin{array}{c}1.6 \\
(0.1)\end{array}$ & 0.383 & $\begin{array}{c}1.6 \\
(0.1)\end{array}$ & $\begin{array}{l}1.6 \\
(0)\end{array}$ & 0.732 & $\begin{array}{c}1.6 \\
(0.1)\end{array}$ & $\begin{array}{c}1.6 \\
(0.1)\end{array}$ & 0.265 \\
\hline Weight (kg); median (IQR) & $\begin{array}{c}66 \\
(54.7,74.8)\end{array}$ & $\begin{array}{c}61.6 \\
(51.5,66.3)\end{array}$ & 0.506 & $\begin{array}{c}65.9 \\
(54.2,74.3)\end{array}$ & $\begin{array}{c}56.2 \\
(52.3,60)\end{array}$ & 0.167 & $\begin{array}{c}66 \\
(55,75)\end{array}$ & $\begin{array}{c}59 \\
(51.4,65.5)\end{array}$ & 0.196 \\
\hline \multicolumn{10}{|l|}{ BMI $\left(\mathrm{kg} / \mathrm{m}^{2}\right)$} \\
\hline $\begin{array}{l}<23 \\
\geq 23\end{array}$ & $\begin{array}{l}23 \\
26\end{array}$ & $\begin{array}{l}9 \\
6\end{array}$ & 0.555 & $\begin{array}{l}27 \\
31\end{array}$ & $\begin{array}{l}5 \\
1\end{array}$ & 0.196 & $\begin{array}{l}20 \\
26\end{array}$ & $\begin{array}{c}12 \\
6\end{array}$ & 0.164 \\
\hline \multicolumn{10}{|l|}{ Technique } \\
\hline \multicolumn{10}{|c|}{ Right adrenal vein level from selection } \\
\hline $\begin{array}{l}\mathrm{T} 11 \\
\mathrm{~T} 12 \\
\mathrm{~L} 1 \\
\end{array}$ & $\begin{array}{l}11 \\
25 \\
13 \\
\end{array}$ & $\begin{array}{l}3 \\
6 \\
4 \\
\end{array}$ & 1.000 & $\begin{array}{l}- \\
- \\
-\end{array}$ & $\begin{array}{l}- \\
- \\
-\end{array}$ & - & $\begin{array}{l}11 \\
23 \\
12 \\
\end{array}$ & $\begin{array}{l}3 \\
8 \\
5 \\
\end{array}$ & 0.975 \\
\hline \multicolumn{10}{|l|}{ Time of procedure } \\
\hline $\begin{array}{l}\text { Morning } \\
\text { Afternoon }\end{array}$ & $\begin{array}{l}31 \\
18 \\
\end{array}$ & $\begin{array}{l}8 \\
7 \\
\end{array}$ & 0.698 & $\begin{array}{l}35 \\
23\end{array}$ & $\begin{array}{l}4 \\
2 \\
\end{array}$ & 1 & $\begin{array}{l}29 \\
17 \\
\end{array}$ & $\begin{array}{c}10 \\
8 \\
\end{array}$ & 0.582 \\
\hline \multicolumn{10}{|l|}{ Route of access } \\
\hline $\begin{array}{l}\text { Right CFV } \\
\text { Left CFV } \\
\text { Both CFVs }\end{array}$ & $\begin{array}{c}44 \\
4 \\
1 \\
\end{array}$ & $\begin{array}{c}14 \\
1 \\
0\end{array}$ & 1 & $\begin{array}{c}53 \\
5 \\
0\end{array}$ & $\begin{array}{l}5 \\
0 \\
1\end{array}$ & 0.115 & $\begin{array}{r}42 \\
4 \\
0\end{array}$ & $\begin{array}{c}16 \\
1 \\
1\end{array}$ & 0.264 \\
\hline \multicolumn{10}{|c|}{ Number of right blood samplings per procedure } \\
\hline $\begin{array}{l}\text { One } \\
\text { Two }\end{array}$ & $\begin{array}{l}30 \\
19 \\
\end{array}$ & $\begin{array}{l}6 \\
7\end{array}$ & 0.249 & $\begin{array}{l}- \\
- \\
\end{array}$ & - & - & $\begin{array}{l}28 \\
18\end{array}$ & $\begin{array}{l}8 \\
8\end{array}$ & 0.237 \\
\hline \multicolumn{10}{|l|}{ Period of procedure } \\
\hline $\begin{array}{l}2009-2103 \\
2014-2016\end{array}$ & $\begin{array}{l}25 \\
24\end{array}$ & $\begin{array}{c}12 \\
3\end{array}$ & 0.091 & $\begin{array}{l}31 \\
27\end{array}$ & $\begin{array}{l}6 \\
0\end{array}$ & $0.035^{*}$ & $\begin{array}{l}22 \\
24\end{array}$ & $\begin{array}{c}15 \\
3\end{array}$ & $0.007^{*}$ \\
\hline
\end{tabular}

${ }^{*} p<0.05$; AVS - adrenal venous sampling, SD - standard deviation, IQR - interquartile range, BMI - body mass index, CFV - common femoral vein

Table 4. Multivariate logistic regression for factors of success of bilateral blood samplings

\begin{tabular}{|c|c|c|c|}
\hline Factors & $\begin{array}{l}\text { Crude odds ratio } \\
(95 \% \mathrm{Cl})\end{array}$ & $\begin{array}{c}\text { Adjusted odds ratio } \\
(95 \% \mathrm{Cl})\end{array}$ & $P$ \\
\hline \multicolumn{4}{|l|}{ Gender } \\
\hline $\begin{array}{l}\text { Female } \\
\text { Male }\end{array}$ & $\begin{array}{c}1 \\
9.97(1.22-81.68)\end{array}$ & $\begin{array}{c}1 \\
9.83(1.14-85.14)\end{array}$ & $0.009^{*}$ \\
\hline \multicolumn{4}{|l|}{ BMI } \\
\hline $\begin{array}{l}<23 \\
\geq 23\end{array}$ & $\begin{array}{c}1 \\
2.6(0.83-8.13)\end{array}$ & $\begin{array}{c}1 \\
1.95(0.55-6.88) \\
\end{array}$ & 0.297 \\
\hline \multicolumn{4}{|c|}{ Period of procedure } \\
\hline $\begin{array}{l}2009-2013 \\
2014-2016 \\
\end{array}$ & $\begin{array}{c}1 \\
5.45(1.39-21.42) \\
\end{array}$ & $\begin{array}{c}1 \\
5.05(1.2-21.16) \\
\end{array}$ & $0.017^{*}$ \\
\hline
\end{tabular}

${ }^{*} p<0.05 ; \mathrm{Cl}$ - confidence interval, BMI - body mass index experienced interventionists [9,17-19]. Previous studies and this current study had similar results, which showed that the success rate of right AVS was lower than for left AVS, and the failure rate of right AVS was about 30\% [4-6, $8-10,12,20]$. The reason for this is the anatomical difficulty of catheterisation of the right adrenal vein due to its small calibre and short length. A cadaveric study confirmed that the diameters of the right and left adrenal veins were $3.5 \mathrm{~mm}$ and $4.5 \mathrm{~mm}$ and the mean lengths of the right and left adrenal veins were $7.0 \mathrm{~mm}$ and $16.0 \mathrm{~mm}$, respectively [21]. Additionally, the right adrenal vein drains directly into the IVC and has more anatomical variations that lead to a difficult catheterisation.

Gender was the factor associated with success of AVS in this study. AVS performed in males was about ten times 
more likely to succeed than in females. The possible reason for this is that the calibre of the adrenal vein in males is larger than in females, which leads to easier catheterisation compared with females. However, from the literature review, there were no data or comparisons between the diameters of the adrenal veins in males and females. One study by Berney et al. [22] reported that male gender might significantly influence the success rate of AVS from a univariate analysis. However, there was no significance from the multivariate analysis.

The period of the procedure was also a significant factor associated with success. The procedure performed in the post-initial three-year period was five times more successful than in the initial five-year period in this study. This result was from systematic changes after the initial period, which included a change to a higher quality machine with large flat-panel displays and high-resolution images. Furthermore, the AVS procedure in the post-initial three-year period was performed by a single interventional radiologist who specialised in venous intervention. Similar results from previous studies $[7,17,23]$ suggested that limiting the AVS procedures to a few interventionists increased the success rate. Therefore, this should be the practice in a low-volume centre.

The study by Berney et al. [22] also showed that body mass index (BMI) was a significant factor associated with success. An increased BMI may increase the intra-abdominal pressure, leading to a decreased adrenal vein flow, which results in an increased calibre of the adrenal vein, which in turn leads to an easier catheterisation. The average BMI in their study was $29 \pm 5.6 \mathrm{~kg} / \mathrm{m}^{2}$ and a BMI near or more than 30 resulted in an increased success rate. However, BMI was not a factor in our study because the mean \pm SD of the BMI was $25.8 \pm 5.1 \mathrm{~kg} / \mathrm{m}^{2}$. The other factors that included age, level of right adrenal vein selec- tion, time of the procedure, route of access, and the number of right blood samplings per operation were not found to be significant in the current study. Similarly, these factors were not reported to be significant in the literature.

A strength of this study is the evaluation of patient characteristics as predictors of success in AVS, which were not well determined in previous studies. There were some limitations in this study. This study was of retrospective design and was performed at a single centre. However, to improve the impact of the study, a prospective design with a multicentre approach should be performed. Another limitation is the small sample sizes in each group of parameters to compare success and failure. However, we improved the results by using univariate analysis and multivariate logistic regression.

In conclusion, the success rate of bilateral AVS in our study was rather high. However, a high success rate of the procedure in a low-volume centre can occur when performed by a few interventionists. Male gender and post-initial procedural period with a gain in experience and skill of the interventionist were two significant predictors for success of the procedure in this study.

\section{Acknowledgments}

The authors thank Professor Virasakdi Chongsuvivatwong of the Epidermiology unit, Faculty of Medicine, Prince of Songkla University, Thailand for editing the manuscript, and special thanks to Glenn K. Shingledecker of the International Affairs Office, Faculty of Medicine, Prince of Songkla University for editing the English.

\section{Conflict of interest}

The authors report no conflict of interest.

\section{References}

1. Degenhart C, Strube H, Betz MJ, et al. CT mapping of the vertebral level of right adrenal vein. Diagn Interv Radiol 2015; 21: 60-66.

2. Rossi GP, Auchus RJ, Brown M, et al. An expert consensus statement on use of adrenal vein sampling for the subtyping of primary aldosteronism. Hypertension 2014; 63: 151-160.

3. Mulatero P, Stowasser M, Loh K, et al. Increased diagnosis of primary aldosteronism, including surgically correctable forms, in centers from five continents. J Clin Endocrinol Metab 2004; 89: 1045-1050.

4. Funder JW, Carey RM, Fardella C, et al. Case detection, diagnosis, and treatment of patients with primary aldosteronism: an endocrine society clinical practice guideline. J Clin Endocrinol Metab 2008; 93 3266-3281.

5. Young WF. Primary aldosteronism: renaissance of a syndrome. Clin Endocrinol 2007; 66: 607-618.

6. Fingeret AL, Lee JA. Adrenal venous sampling in primary hyperaldosteronism. Curr Surg Rep 2014; 2: 38.
7. Young WF, Stanson AW. What are the keys to successful adrenal venous sampling (AVS) in patients with primary aldosteronism? Clin Endocrinol 2009; 70: 14-17.

8. Daunt N. Adrenal vein sampling: how to make it quick, easy, and successful. Radiographics 2005; 25: S143-S158.

9. Magill SB, Raff H, Shaker JL, et al. Comparison of adrenal vein sampling and computed tomography in the differentiation of primary aldosteronism. J Clin Endocrinol Metab 2001; 86: 1066-1071.

10. Onozawa S, Murata S, Tajima H, et al. Evaluation of right adrenal vein cannulation by computed tomography angiography in 140 consecutive patients undergoing adrenal venous sampling. Eur J Endocrinol 2014; 170: 601-608.

11. Kahn SL, Angle JF. Adrenal vein sampling. Tech Vasc Interventional Rad 2010; 13: 110-125.

12. Stowasser M. Improving the success and reliability of adrenal venous sampling: focus on intraprocedural cortisol measurement. Clin Chem 2012; 58: 1275-1277. 
13. Doppman JL, Gill JR Jr. Hyperaldosteronism: sampling the adrenal veins. Radiology 1996; 198: 309-312.

14. Jakobsson H, Farmaki K, Sakinis A, et al. Adrenal venous sampling: the learning curve of a single interventionalist with 282 consecutive procedures. Diagn Interv Radiol 2018; 24: 89-93.

15. Morita S, Yamazaki H, Sonoyama Y, et al. Successful adrenal venous sampling by non-experts with reference to CT images. Cardiovasc Intervent Radiol 2016; 39: 1001-1006.

16. Siracuse JJ, Gill HL, Epelboym I, et al. The vascular surgeon's experience with adrenal venous sampling for the diagnosis of primary hyperaldosteronism. Ann Vasc Surg 2014; 28: 1266-1270.

17. Young WE, Stanson AW, Thompson GB, et al. Role of adrenal venous sampling in primary aldosteronism. Surgery 2004; 136: 1227-1235.

18. Vonend O, Ockenfels N, Gao X, et al. Adrenal venous sampling: evaluation of the German Conn's registry. Hypertension 2011; 57: 990-995.
19. Oh EM, Lee KE, Yoon K, et al. Value of adrenal venous sampling for lesion localization in primary aldosteronism. World J Surg 2012; 36: 2522-2527.

20. Georgiades CS, Hong K, Geschwind JF, et al. Adjunctive use of $\mathrm{C}$-arm CT may eliminate technical failure in adrenal vein sampling. J Vasc Interv Radiol 2007; 18: 1102-1105.

21. Monkhouse WS. Khalique A. The adrenal and renal veins of man and their connections with azygos and lumbar veins. J Anat 1986; 146: 105-115.

22. Berney M, Maillard M, Doenz F, et al. Clinical determinants of adrenal vein sampling success. Cardiovasc Med 2018; 21: 227-233.

23. Harvey A, Kline G, Pasieka JL. Adrenal venous sampling in primary hyperaldosteronism: Comparison of radiographic with biochemical success and the clinical decision-making with "less than ideal" testing. Surgery 2006; 140: 847-853. 